Note: This is a draft of a paper submitted for publication. Contents of this paper should not be quoted or referred to without permission of the author(s).

Submitted at the Fall 2000 Materials Research Society Meeting

Symposium Proceedings, "Microstructural Processes in Irradiated Materials"

\title{
Ion-Irradiation-Induced Amorphization of Cadmium Niobate Pyrochlore
}

\author{
A. Meldrum, ${ }^{1}$ K. Beaty, ${ }^{1}$ L. A. Boatner, ${ }^{2}$ and C. W. White ${ }^{2}$. \\ ${ }^{1}$ Department of Physics, University of Alberta, Edmonton, AB T6G Canada \\ ${ }^{2}$ Solid State Division, Oak Ridge National Laboratory, Oak Ridge, TN 37831
}

The submitted manuscript has been authored by a
contractor of the U.S. Government under contract
No. DE-AC05-00OR 22725 . Accordingly, the
U.S. Government retains a nonexclusive, royalty-
free license to publish or reproduce the published
form of this contribution, or allow others to do
so, for U.S. Government purposes."

Prepared by the

SOLID STATE DIVISION

OAK RIDGE NATIONAL LABORATORY

Managed by

UT-BATTELLE, LLC, for the

U.S. DEPARTMENT OF ENERGY

Under Contract No. DE-AC05-00OR22725 


\title{
ION-IRRADIATION-INDUCED AMORPHIZATION OF CADMIUM NIOBATE PYROCHLORE
}

\author{
A. Meldrum and K. Beaty, Dept. of Physics, University of Alberta, Edmonton AB, T5N \\ 2A3, Canada \\ L. A. Boatner and C. W. White, Solid State Division, Oak Ridge National Laboratory, \\ Oak Ridge TN 37831 USA
}

\section{Introduction}

Pyrochlores represent a large class of compounds with the general chemical formula $\mathrm{A}_{2} \mathrm{~B}_{2} \mathrm{O}_{7}$. The pyrochlore structure consists of interconnected $\mathrm{AO}_{8}$ and $\mathrm{BO}_{6}$ cation polyhedra [1] where the $\mathrm{BO}_{6}$ octahedra are slightly distorted and form a continuous corner-sharing network. The large, 8-fold coordinated A-site cations and the seventh oxygen occupy channels in the $\left(\mathrm{B}_{2} \mathrm{O}_{6}\right)_{\infty}$ network of octahedra [1,2]. The structure is an anion-deficient $\mathrm{MX}_{2}$ fluorite structure in which the $\mathrm{A}$ and $\mathrm{B}$ cations are ordered on the $\mathrm{M}$ sites. One eighth of the $\mathrm{X}$ anions are absent in the pyrochlore structure, and the resulting oxygen vacancies are ordered on the anion sublattice [2].

Recent in-situ ion irradiation experiments have focused on the effects of chemical composition and incident ion mass and energy on the irradiation-induced amorphization of several pyrochlore compositions. $\mathrm{Gd}_{2} \mathrm{Ti}_{2} \mathrm{O}_{7}$ has been the subject of considerable study since it is one of the three main actinide-bearing phases of SYNROC, - a polyphase ceramic waste form proposed for the disposition of high-level nuclear waste. Replacement of the Gd with other lanthanide elements or $\mathrm{Ca}$ has been found to have a relatively minor effect on the kinetics of irradiation-induced amorphization; however, the substitution of $\mathrm{Ti}$ with $\mathrm{Zr}$ in increasing concentrations sharply increases the resistance to amorphization even at cryogenic temperatures [3]. Pyrochlore containing a variety of Asite cations, including mixtures of $\mathrm{Ca}, \mathrm{U},[4,5]$ and various lanthanides [6] are easily amorphized at room temperature, and in fact, amorphization can be induced at temperatures as high as $1030 \mathrm{~K}$.

The previous studies of radiation damage effects in pyrochlores have employed either impure natural crystals with relatively uncertain geological histories or polycrystalline synthetic, pressed and sintered pellets. All previous ion-beam investigations have used pyrochlores of the $+3,+4$ cation valence group. In the present work, we investigate the effects of ion irradiation using relatively large (up to $15 \times 15 \times 5 \mathrm{~mm}$ ) high-purity synthetic single crystals of the cadmium/niobium $+2,+5$ pyrochlore, $\mathrm{Cd}_{2} \mathrm{Nb}_{2} \mathrm{O}_{7}$.

\section{Experimental}

Crystals of $\mathrm{Cd}_{2} \mathrm{Nb}_{2} \mathrm{O}_{7}$ were grown by means of a high-temperature solvent (flux) technique. The resulting single crystals were prepared for the in-situ ion-irradiation/TEM analysis experiments by hand polishing to a thickness of approximately $10 \mu \mathrm{m}$ and subsequent ion milling to perforation at room temperature using $4 \mathrm{keV} \mathrm{Ar}^{+}$ions at an incident angle of $20^{\circ}$. These specimens were then irradiated in-situ in an electron microscope at the HVEM-Tandem Facility at Argonne National Laboratory [7]. The irradiations were carried out with either $1200 \mathrm{keV} \mathrm{Xe}{ }^{2+}$ or $280 \mathrm{keV} \mathrm{Ne}^{+}$ions at 
temperatures from 20 to $1100 \mathrm{~K}$. The ion flux was $1.7 \times 10^{12} \mathrm{~cm}^{-2} \mathrm{~s}^{-1}$. The electron microscope was operated at $300 \mathrm{kV}$, and the electron beam was not incident on the specimen for most of the ion-irradiation time. Selected-area electron diffraction was used to determine the dose necessary to amorphize the specimen. The experiments were continued until the electron-diffraction maxima disappeared, as determined by visual examination of the phosphor screen, and the electron-diffraction pattern consisted only of the diffuse halo characteristic of an amorphous material. The thickness of the specimens was estimated to be $\sim 100 \mathrm{~nm}$ by using combined thickness-fringe and convergent-beam electron-diffraction measurements. The room-temperature experiments were repeated three times in order to estimate the mean deviation. This was converted to a percentage of the average valuc, and the same percentage was used to calculate error bars on all the data points.

The $\mathrm{Cd}_{2} \mathrm{Nb}_{2} \mathrm{O}_{7}$ crystals that also exhibited high-quality growth faces were selected for use in the combined ion implantation and RBS analysis experiments. The most highly developed growth faces corresponded to $\{111\}$ family of crystallographic planes, and these were used for most of the experiments. The specimens were mounted by springclipping onto a steel backing plate for ion implantation. One half of each sample was masked and was not implanted. The beam current was less than $0.5 \mu \mathrm{A} / \mathrm{cm}^{2}$ so thermally conductive paint was not applied. The duration of the implant was from seconds to a few minutes. All of the implantations were carried out at room temperature. The samples were tilted $7^{\circ}$ away from the incident ion beam to minimize channeling effects.

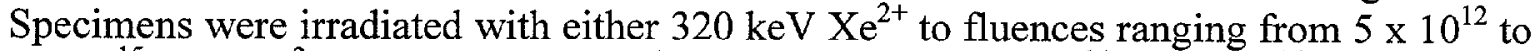
$1 \times 10^{15}$ ions $/ \mathrm{cm}^{2}$, or with $70 \mathrm{keV} \mathrm{Ne}$ to fluences from $3 \times 10^{14}$ to $1 \times 10^{16}$ ions $/ \mathrm{cm}^{2}$. At these energies, both ion types have a projected range of approximately $60 \mathrm{~nm}$. The specimens were implanted to a low ion fluence and were then removed from the implanter, and Rutherford Backscattering analysis (RBS) in the channeling mode was performed using a $2.3 \mathrm{MeV} \mathrm{He}^{+}$ion beam with the detector at an angle of $160^{\circ}$ relative to the incident $\mathrm{He}^{+}$beam. Each specimen was initially aligned in the usual manner by finding the minimum yield in the unimplanted (masked) portion of the crystal. The specimen was then linearly translated so that the He beam impinged on the implanted region of the crystal, and a new spectrum was obtained. Random yields were obtained by tilting the unirradiated part of the crystal away from the zone axis and then rotating over an angle of $\pm 5^{\circ}$ during data collection. The specimens were subsequently returned to the ion implanter for the accumulation of an additional ion dose, and the process was repeated until the channeling yield from the near-surface region matched the random yield.

\section{Results and Discussion}

\section{In-situ experiments}

$\mathrm{Cd}_{2} \mathrm{Nb}_{2} \mathrm{O}_{7}$ was amorphized at room temperature by both the $\mathrm{Ne}^{+}$and $\mathrm{Xe}^{2+}$ irradiations. At low fluences (i.e., less than one third of the total fluence for amorphization), the $\{022\}$ diffraction maxima from the pyrochlore lattice gradually disappeared, but the $\{044\}$ maxima remained intense (Fig. 1). With increasing dose, the $\{044\}$ diffraction spots gradually decreased in intensity, and concurrently, a diffraction halo characteristic of an 

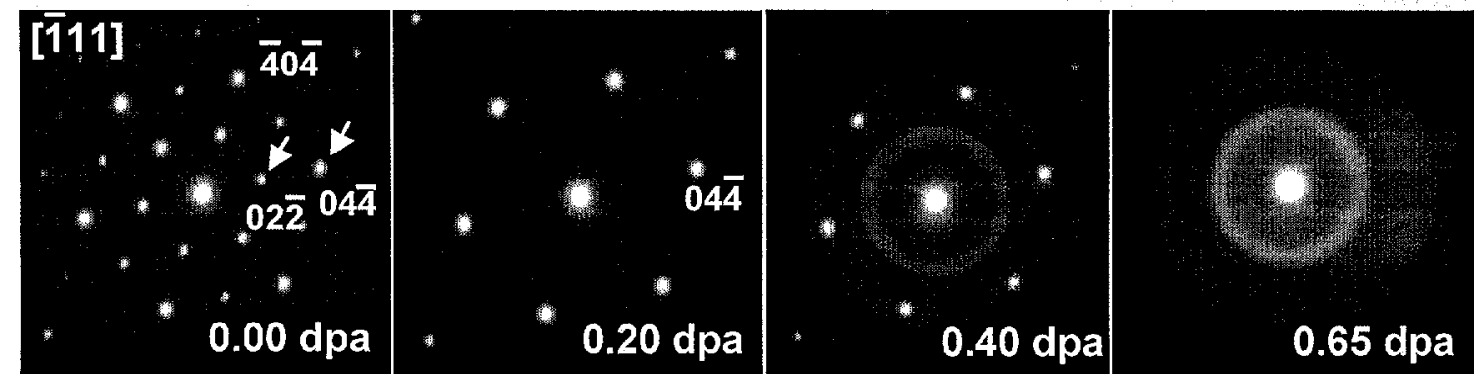

Fig. 1. Electron-diffraction patterns for $\mathrm{Cd}_{2} \mathrm{Nb}_{2} \mathrm{O}_{7}$ irradiated with $280 \mathrm{keV} \mathrm{Ne}{ }^{+}$. The dose is given in the bottom right corner of each diffraction pattern.

amorphous phase increased in intensity. The electron-diffraction patterns presented in Figure 1 for the case of $\mathrm{Ne}^{+}$irradiation show that, in fact, $\mathrm{Cd}_{2} \mathrm{Nb}_{2} \mathrm{O}_{7}$ does not become amorphous directly, but rather that it transforms to the disordered defect-fluorite structure at intermediate ion doses. Disordering prior to amorphization has been observed in several other pyrochlore compositions [4-6]. The ion fluence required for the amorphization of $\mathrm{Cd}_{2} \mathrm{Nb}_{2} \mathrm{O}_{7}$, as measured by electron diffraction, is given in Table 1 . These values were converted to an amorphization dose $\left(D_{c}\right)$ in dpa, using SRIM to determine the number of displacements per ion over the thickness of the specimen (the displacement energy was assumed to be 25 $\mathrm{eV}$ to be consistent with previous studies). The temperature dependence of the amorphization dose for the $\mathrm{Ne}^{+}$and $\mathrm{Xe}^{2+}$ ion irradiation of $\mathrm{Cd}_{2} \mathrm{Nb}_{2} \mathrm{O}_{7}$ is plotted in Fig. 2. For $\mathrm{Ne}^{+}$irradiation, the amorphization dose is relatively constant at $\sim 0.3 \mathrm{dpa}$ at temperatures below $\sim 150 \mathrm{~K}$, compared to $0.09 \mathrm{dpa}$ for $\mathrm{Xe}^{2+}$ irradiation. At higher temperatures, the amorphization dose increases rapidly.

Table 1. Ion fluence for amorphization of $\mathrm{Cd}_{2} \mathrm{Nb}_{2} \mathrm{O}_{7}$ pyrochlore.

\begin{tabular}{|c|c|c|}
\hline Ion & $\begin{array}{c}\text { Temperature } \\
\text { (K) } \\
\end{array}$ & $\begin{array}{c}\text { Fluence } \\
\times 10^{14} \text { ions } / \mathrm{cm}^{2} \\
\end{array}$ \\
\hline $\mathrm{Ne}^{+}$ & 20 & 11.1 \\
\hline \multirow[t]{4}{*}{$(280 \mathrm{keV})$} & 100 & 11.4 \\
\hline & 130 & 12.9 \\
\hline & 303 & 25.5 \\
\hline & 403 & 36.6 \\
\hline $\mathrm{Xe}^{2+}$ & 20 & 0.3 \\
\hline \multirow[t]{6}{*}{$(1200 \mathrm{keV})$} & 130 & 0.3 \\
\hline & 303 & 0.7 \\
\hline & 473 & 0.9 \\
\hline & 573 & 2.0 \\
\hline & 623 & 17.0 \\
\hline & 673 & 44.2 \\
\hline
\end{tabular}

Several models have been developed that relate the amorphization dose to temperature and thereby define the critical temperature and activation energy for recrystallization [8-13]. The lines in Fig. 2 were plotted using a recent amorphizationrecrystallization model that assumes that recrystallization is maximized when there is a maximum amount of amorphouscrystalline interface:

$\frac{d f_{a}}{d t}=P\left(1-f_{a}\right)-\lambda ?_{a} f_{a}\left(1-f_{a}\right)$

In Eq. $1, f_{a}$ is the amorphous fraction, $t$ is time, $P$ is the dose rate $(\mathrm{dpa} / \mathrm{s})$, and $\lambda$ is the rate of epitaxial thermal recrystallization. Equation (1) can be solved for the amorphization dose, $D$ : 


$$
D_{c}=\frac{\ln P-\ln \frac{P-\lambda_{a} f_{a}}{1-f_{a}} \sqrt{y}}{\frac{\lambda_{a}}{P}-1 \sqrt{ } ? C}
$$

where $C$ is a scaling parameter that relates the damage production rate to the KinchinPease displacement rate. The thermal term, $\lambda$, maximizes for $f_{a}=0.5$, when there is the most crystalline-amorphous interface. Unlike a more detailed model currently being developed for the case of direct impact amorphization [14], Eq. 1 does not strictly speaking - say anything about the mechanism of amorphization, except that that recrystallization is most efficient when $f_{a}=0.5$. The recrystallization term can be written as:

$\lambda=\tau_{\lambda} \exp \frac{-E_{\lambda}}{k T}$

Values for $\tau_{\lambda}$ and $E_{\lambda}$ were varied to obtain the best visual fit to the data in Fig. 2. The critical temperature is then given by:

$$
T_{c}=\frac{-E_{\lambda}}{k \ln \frac{P}{\tau_{\lambda}} \bigvee}
$$

The values obtained for $\tau_{\kappa}$ and $E_{\kappa}$ and $T_{c}$ are given in Table 2 .

Table 2. Comparison of activation energies and critical temperatures obtained by solving Equations 3 and 6 . The amorphization dose at $0 \mathrm{~K}$ (extrapolated) and at room temperature are

\begin{tabular}{|c|c|c|c|c|c|c|}
\hline \multirow[t]{2}{*}{ ion } & \multicolumn{2}{|c|}{$E_{a}(e V)$} & \multicolumn{2}{|c|}{$T_{c}(K)$} & \multirow{2}{*}{$\begin{array}{c}D_{0}(0 K) \\
\text { dpa }\end{array}$} & \multirow{2}{*}{$\begin{array}{c}D_{c}(R T) \\
\text { dpa }\end{array}$} \\
\hline & Eq. 3 & $\mathrm{Eq} \cdot 6$ & Eq. 3 & Eq. 6 & & \\
\hline $\mathrm{Ne}^{+}$ & 0.04 & 0.04 & 580 & 480 & 0.28 & 0.65 \\
\hline $\mathrm{Xe}^{2+}$ & 0.01 & 0.08 & 695 & 620 & 0.09 & 0.22 \\
\hline
\end{tabular}
given in the final two columns.

\section{Ion Irradiation and RBS-Channeling}

The results of the RBS channeling measurements are summarized in Fig. 3, which also shows the RBS data for an unimplanted $\mathrm{Cd}_{2} \mathrm{Nb}_{2} \mathrm{O}_{7}$ (111) surface for purposes of comparison. The channeling spectrum for the unimplanted samples was characterized by 
a minimum yield in the range of 3 $5 \%$, and the surface peaks for $\mathrm{Nb}$ and $\mathrm{Cd}$ are clearly distinguishable. With increasing ion dose $\left(\mathrm{Ne}^{+}\right.$or $\left.\mathrm{Xe}^{2+}\right)$, the minimum yield from the channeling spectrum increased relatively rapidly initially and subsequently increased more slowly with increasing ion dose. Finally, at the highest doses, the RBS spectra match the random value in the nearsurface region.

Interpretation of the RBS data is difficult because the $\mathrm{Cd}$ and $\mathrm{Nb}$ damage peaks overlap. As a first approximation, we subtracted the unimplanted spectrum from the implanted spectra in order to remove surface peak contributions. The $\mathrm{Cd}$ peak for the intermediate damage spectra became resolvable at channel 900 , corresponding to a backscattered He energy of 1975 $\mathrm{keV}$. Using the surface energy
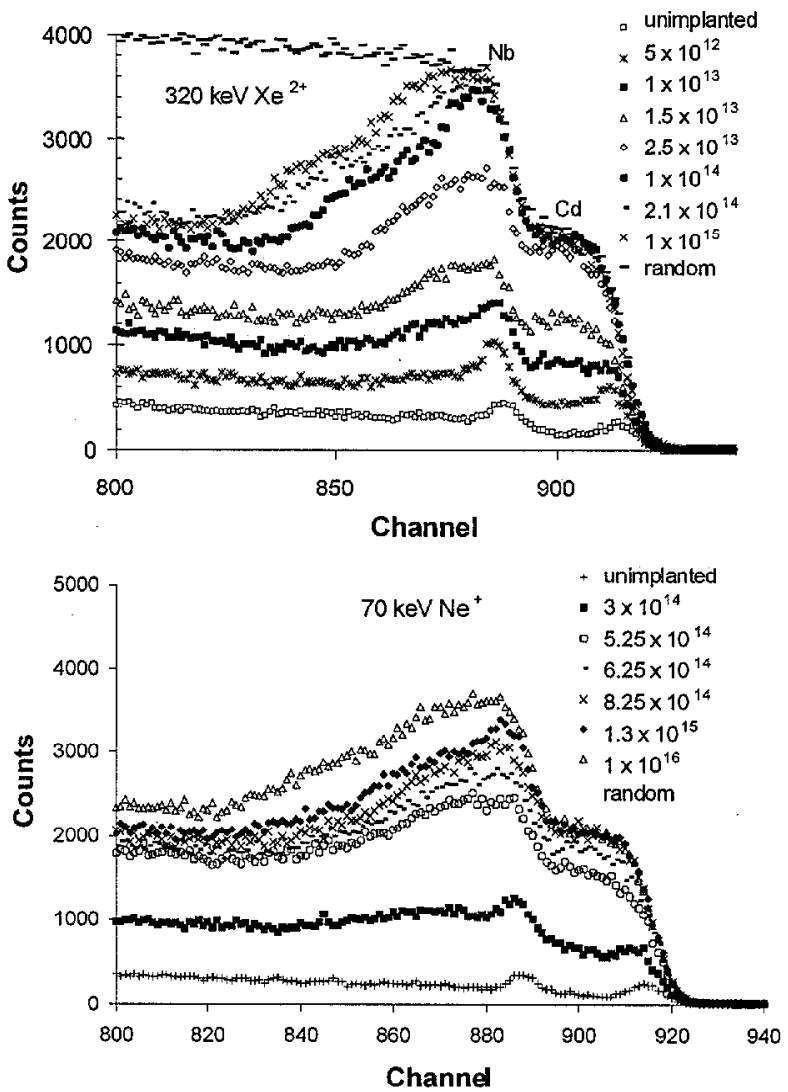

Fig. 3. RBS-Channeling results for $\mathrm{Cd}_{2} \mathrm{Nb}_{2} \mathrm{O}_{7}$. approximation, this corresponds to a depth of $34 \mathrm{~nm}$ for the maximum damage peak, compared to $43 \mathrm{~nm}$ predicted by SRIM. In order to obtain the disordered fraction on the $\mathrm{Cd}$ sublattice, we simply used the ratio $I / I_{r}$ obtained from Figure 3. A more accurate analysis would take into account dechanneling effects by using a linear dechanneling approximation [15]. In the present case, because of the shallow depth of the damage peak, the short range of the incident ions, and because of the difficulty in applying the linear dechanneling approximation to these spectra (there is no way to determine where the end of the $\mathrm{Cd}$ damage region is actually located), we felt that the best approximation would be obtained by ignoring dechanneling effects. Using these assumptions, the disordered fraction on the Cd sublattice is plotted as a function of dose in Figure 4. Because the slope of the decrease in the $\mathrm{Cd}$ yield cannot be accurately determined, however, the $\mathrm{Nb}$ data are probably too unreliable for an independent estimation of the disordered fraction. The curves in Fig. 4 were plotted using the well-known Gibbons'

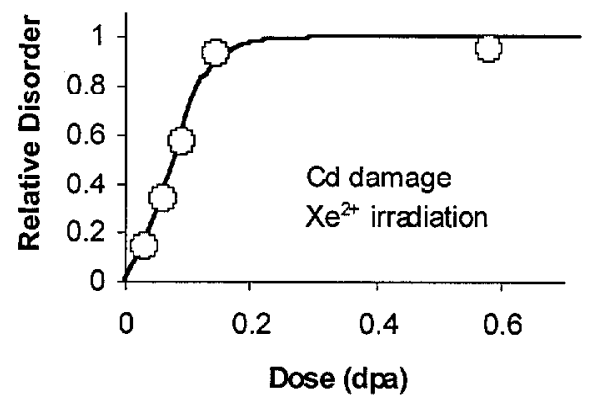

Fig. 4. Relative disorder on the $\mathrm{Cd}$ sublattice vs. $320 \mathrm{keV} \mathrm{Xe}^{2+}$ ion dose, as obtained from the RBS results. The solid line is Gibbons' "double overlap" model. The results for $\mathrm{Ne}+$ irradiation were similar. 
model $\left[{ }^{16}\right]$ for disorder accumulation with increasing dose. For both $\mathrm{Ne}^{+}$and $\mathrm{Xe}^{2+}$ irradiation, the best-fit curves suggests that amorphization does not occur within individual collision cascades, but may take place more gradually as cascades accumulate and overlap, which is consistent with the electron diffraction results in Fig. 1.

\section{Further Discussion and Conclusion}

The results show that $\mathrm{Cd}_{2} \mathrm{Nb}_{2} \mathrm{O}_{7}$ is more susceptible to irradiation-induced amorphization below room temperature than the titanate pyrochlores, but that recovery is more efficient at high temperatures. Sickafus ct al. [17] suggested that irradiation-induced amorphization in $+3,+4$ pyrochlores is controlled by cation radius ratios through their influence on antisite defect formation energies. Accordingly, phases which have radius ratios close to $1: 1$ have low antisite defect energies and can accommodate radiation damage by cation disordering, without amorphization. $\mathrm{Cd}_{2} \mathrm{Nb}_{2} \mathrm{O}_{7}$ has an $\mathrm{A}: \mathrm{B}$ cation radius ratio of 1.72:1 (radii from Ref. 18), similar to that of $\mathrm{Gd}_{2} \mathrm{Ti}_{2} \mathrm{O}_{7}$ (1.74:1). Taking either $T_{c}$ or room-temperature $D_{c}$ (Table 3 ) as a measure of the radiation resistance shows that $\mathrm{Gd}_{2} \mathrm{Ti}_{2} \mathrm{O}_{7}$ and $\mathrm{Cd}_{2} \mathrm{Nb}_{2} \mathrm{O}_{7}$ are, however, quite different. If the defect energy picture of amorphization is valid, the relationship between the radius ratios and the antisite defect energies in the $+2,+5$ pyrochlores must be very different from the $+3,+4$ phases.

\section{Acknowledgements}

The HVEM-Tandem Facility staff assisted with the irradiations. Bill Weber improved the interpretation of the RBS data. AM is supported by NSERC Canada. LAB is supported by the USDOE, Division of Mat. Sci., and RCE by BES/USDOE Grant \# DE-FG0297ER45656. V. Keppens and J. Ramey grew the $\mathrm{Cd}_{2} \mathrm{Nb}_{2} \mathrm{O}_{7}$ crystals. ORNL is managed by the USDOE under contract DE-AC05-00OR22725 (UT-Battelle, LLC).

\section{References}

[1] R.A. McCauley, J. Appl. Phys. 51, 290 (1980).

[2] E. Aleshin and R. Roy, J. Am. Ceram. Soc. 45, 18 (1962).

[3] S.X. Wang, B.D. Begg, L.M. Wang, R.C. Ewing, W.J. Weber, and K.V.G. Kutty, J. Mater. Res. 14, 4470 (1999).

[4] K.L. Smith, N.J. Zaluzec, and G.R. Lumpkin, J. Nucl. Mater. 250, 36 (1997).

[5] S.X. Wang, L.M. Wang, R.C. Ewing, G.S. Was, and G.R. Lumpkin, Nucl. Instr. Meth. B149, 704 (1999).

[6] S.X. Wang, L.M. Wang, R.C. Ewing, and K.V.G. Kutty, Nucl. Instr. Meth. B169, 135 (2000).

[7] C.W. Allen and E.A. Ryan, Mat. Res. Soc. Symp. Proc. 439, 277 (1997).

[8] K.A. Jackson, J. Mater. Res. 3, 1218 (1988).

[9] W.J. Weber, R.C. Ewing, and L.M. Wang, J. Mater. Res. 9, 688 (1994).

[10] W.J. Weber, Nucl. Instr. Meth. 166, 98 (2000).

[11] G. Carter and M.J. Nobes. J. Mater. Res. 6, 2103 (1991).

[12] V. Heera, T. Henkel, R. Kögler, and W. Skorupa, Phys. Rev. B 52, 15776 (1995).

[13] S.X. Wang, L.M. Wang, R.C. Ewing, and R.H. Doremus, J. Non-Cryst. Sol. 238, 198 (1998).

[14] A. Meldrum, Mat. Res. Soc. Symp. Proc. (these proceedings).

[15] O.W. Holland, D. Fathy, J. Narayan, and O.S. Oen, Radiat. Eff. 90, 127 (1985).

[16] J.F. Gibbons, Proc. IEEE 60, 1062 (1972). 
[17] K.E. Sickafus, L. Minervini, R.W. Grimes, J.A. Valdez, M. Ishimaru, F. Li, K.J. McClellan, and T. Hartmann, Science 289, 748 (2000).

[18] R.D. Shannon, Acta Cryst. A32, 751 (1976). 